\title{
A CASE OF LEIOMYOMA OF THE IRIS*
}

BY

\section{A. STANWORTH \\ Manchester}

LeIomyomata of the iris are rare tumours, only eight or nine having been reported. Most of these were diagnosed clinically as sarcomata, the true diagnosis being made only on histological examination; so far as I am aware the present case is the first in which the presumptive diagnosis was made on clinical grounds alone.

\section{Case Report}

The patient, a lady aged 58 years, attended the Manchester Royal Eye Hospital on January 11, 1950, having experienced a sudden loss of vision in the left eye after stooping the previous day. The only relevant history was a fall $2 \frac{1}{2}$ years before, as a result of which she had been cut around the eyes, without any definite ocular injury. On examination, the right eye was normal, the corrected vision being $6 / 9$. The left vision was counting fingers only. There was a hyphaema extending over the lower half of the iris and pupillary area, obscuring a swelling projecting forwards from the lower quandrant of the iris. The next day the hyphaema was much smaller and her corrected vision was $6 / 6$ partly. She was admitted for investigation under Dr. W. Stirling.

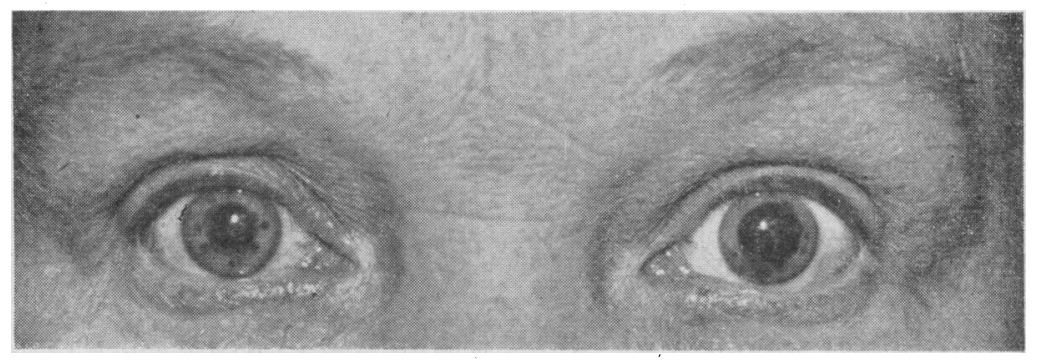

FIG. 1.-General appearance of iris swelling in left eye.

The iris tumour was situated in the lower nasal quadrant (Fig. 1). It appeared to arise from the middle third of the iris, the apex being free of the pupil, though projecting over it; the peripheral margin of the iris was also clear of the tumour. The swelling had a lightly pigmented irregular surface, with a few large superficial blood vessels which were presumably the source of the hyphaema. The remainder of the iris was normal, and no exudates or keratic precipitates were seen. The pupil dilated quite well, but not fully, with homatropine and cocaine; it was thought that the failure to dilate fully was due to the mechanical effect of the swelling rather than to an invasive character of the tumour. In the sector of the lens immediately behind the swelling there was an anterior lens opacity, the remainder of the lens being clear. Accommodation was normal and equal in both eyes; the fundi and ocular tension was normal and the fields full. Transillumination was negative, and the swelling was not translucent. The Wassermann reaction was negative.

* Received for publication May 19, 1950. 
The diagnosis of "benign tumour, probably leiomyoma" was made. On February 10, 1950, Dr. Stirling performed an iridectomy, the tumour being completely removed, together with the surrounding iris. Apart from an operative hyphaema, which cleared rapidly, convalescence was uneventful. The lens opacity was now seen to be largely subcapsular, with striae running into the anterior layers of the cortex.

Pathological Report.-The specimen was examined by Dr. J. Wainwright, who reported as follows :

Histology of Tumour of the Iris.-There is a small tumour about $2 \mathrm{~mm}$. in length on the anterior surface of the iris, which appears to arise from the smooth muscular fibres lying beneath the pigment layers. It consists of interwoven bundles of smooth muscle fibres, some of which are cui longitudinally, others transversely. The cells are of spindle type with uniform rod-shaped nuclei. No mitoses are present. The cytoplasm is stained yellow with van (jeison, but it is not possible to demonstrate myofibrils with Mallory's phosphotungstic acid haematoxylin. In the deeper part of the tumour the muscle bundles are separated by remains of the collagenous stroma of the iris, but in the superficial parts there are no fibrils staining pink with van Geison stain. Pigment granules are included in the deeper part of the tumour, but are not seen within spindle cells. The appearances are those of leiomyoma of the iris. The failure to show myofibrils is not significant since these are not invariably found in leiomyoma arising in other regions of the body.

The microscopic appearances are shown in Figs. 2 and 3.

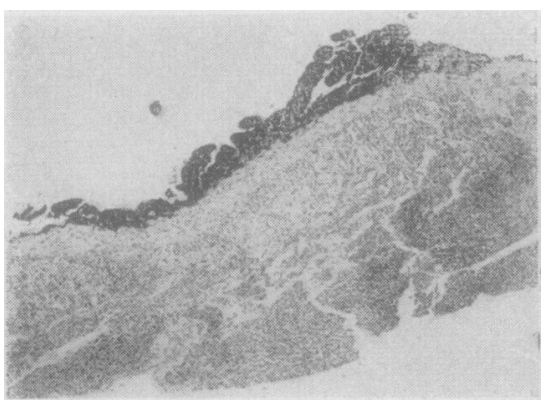

Fig. 2.-Histology of tumour. Haematoxylin and Eosin. 35 .

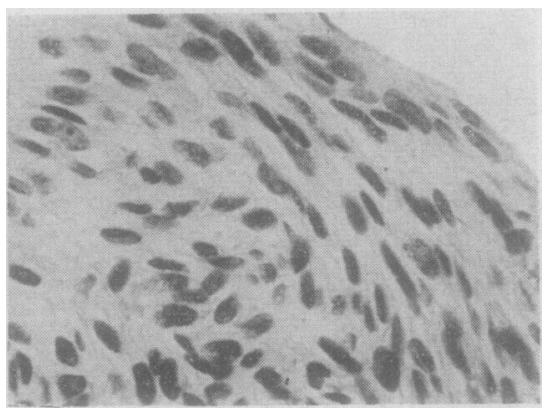

FIG. 3.-Histology of tumour. Van Gieson. $\quad 300$

\section{Discussion}

The literature on leiomyoma of the iris has recently been summarized by Fleming (1948) and O' Day (1949), each of whom report an additional case. The points on which a clinical diagnosis of leiomyoma was made in the present case were :

(1) The total absence of inflammatory signs.

(2) The absence of any invasive characteristics of the tumour such as a marked interference with pupillary reactions or extension to the angle of the anterior chamber.

(3) The presence of hyphaema, which has been described in many of the reported cases (Van Duyse, 1911; Verhoeff, 1923; Ellett, 1939; O'Day, 1949). 
(4) The site, as in all previous cases, in the lower half of the iris.

(5) The presence of a cataract localized to the area behind the swelling; this was taken to indicate that the swelling had probably been present for some time. A cataract was present behind the tumour in the patients described by Ellett (1939) and O'Day (1949).

(6) The absence of gross pigmentation. In general the published descriptions of leiomyomata show the tumours to be about the same colour as the iris, though one (Frost, 1936) is described as being dotted with pigment, and two others as becoming gradually darker (Ellett, 1939; Fleming, 1948), the latter being diagnosed originally as a malignant melanoma.

It was, of course, impossible to be certain that the condition was not a sarcoma of the iris, as all the above criteria, with the possible exception of the cataract, may well be present in an early sarcoma. Nevertheless, sarcomata are prone to invade the angle of the anterior chamber early and are commonly more pigmented than was the present tumour. It seems justifiable, therefore, to consider any tumour satisfying the above criteria as a probable leiomyoma, and to treat it by iridectomy.

\section{Summary}

Clinical and histological details are reported of a leiomyoma of the iris, and the typical features which enabled a clinical diagnosis to be made are discussed.

I wish to thank Dr. W. Stirling for permission to report this case, and Dr. J. Wainwright for the pathological report.

\section{REFERENCES}

Ellet T, E. C. (1939). Arch. Ophthal. Chicago, 21, 497.

FLEMING, N. (1948). British Journal of Ophthalmology, 32, 885.

Frost, A. D. (1936). Arch. Ophthal., Chicago, 16, 892.

O'DAY, K. (1949). British Journal of Ophthalmology, 33, 283.

VAN Duyse. (1911). Arch. Ophtal., Paris, 31, 13.

VERHOEFF, F. H. (1923). Arch. Ophthal., Chicago, 52, 132. 